\title{
Serum glycan-binding IgG antibodies in HIV-1 infection and during the development of broadly neutralizing responses
}

\author{
Cathrine Scheepers ${ }^{\mathrm{a}, \mathrm{b}}$, Sudipa Chowdhury ${ }^{\mathrm{c}}$, W. Shea Wright ${ }^{\mathrm{c}}$, \\ Christopher T. Campbell ${ }^{c}$, Nigel J. Garrett ${ }^{d}$, \\ Quarraisha Abdool Karim ${ }^{\text {d,e }}$, Salim S. Abdool Karim ${ }^{\text {d,e }}$, \\ Penny L. Moore ${ }^{a, b, d}$, Jeffrey C. Gildersleeve ${ }^{c}$ and Lynn Morris ${ }^{a, b, d}$
}

\begin{abstract}
Background: The HIV-1 envelope is covered with glycans that provide structural integrity and protect conserved regions from host antibody responses. However, these glycans are often the target of broadly neutralizing antibodies (bNAbs) that emerge in some HIVinfected individuals. We aimed to determine whether antiglycan $\lg G$ antibodies are a general response to HIV-1 infection or specific to individuals who develop bNAbs.

Methods: IgG binding to glycans was assessed using arrays that contained 245 unique components including $\mathrm{N}$-linked carbohydrates, glycolipids, and Tn-peptides. Sera from 20 HIV-negative and 27 HIV-positive women (including 12 individuals who developed bNAbs) were profiled longitudinally. HIV-1 gp120 proteins were used to compete for binding to the array.

Results: Antiglycan IgG antibodies fluctuated over a 3-year period, irrespective of HIV infection. However, HIV-positive individuals had elevated binding to 40 components on the array that included $\mathrm{Man}_{8}, \mathrm{Man}_{9}, \mathrm{Tn}$-peptides, heat shock protein, and glycolipids. Competition experiments confirmed that a proportion of these glycan-binding IgG antibodies were HIV-1-specific, some of which were higher in individuals who developed bNAbs.

Conclusions: HIV-1 infection is associated with elevated levels of IgG antibodies to specific glycans. Furthermore, some antiglycan IgG antibodies were more abundant in individuals with bNAbs, suggesting a unique phenotype that may be informative for HIV vaccine design.

Copyright @ 2017 Wolters Kluwer Health, Inc. All rights reserved.
\end{abstract}

AIDS 2017, 31:2199-2209

Keywords: broadly neutralizing antibodies, glycan arrays, high mannose

$N$-linked glycans, HIV-1 infection, Tn-peptides

\section{Introduction}

A comprehensive understanding of the immune response to HIV-1 infection is critical for the development of a vaccine. Antibodies targeting the viral envelope can be detected as early as 12 days postinfection, and even though these bind gp41, they are unable to neutralize the virus [1]. These are followed by strain-specific

\footnotetext{
${ }^{a}$ Centre for HIV and STIs, National Institute for Communicable Diseases of the National Health Laboratory Service, Johannesburg, South Africa, ${ }^{\mathrm{b}}$ School of Pathology, University of the Witwatersrand, Johannesburg, South Africa, ${ }^{\mathrm{C}}$ Chemical Glycobiology Section of the Chemical Biology Laboratory, National Cancer Institute, Frederick, Maryland, USA, ${ }^{\mathrm{d}}$ Centre for the AIDS Programme of Research in South Africa (CAPRISA), KwaZulu-Natal, South Africa, and ' Department of Epidemiology, Columbia University, New York City, New York, USA.

Correspondence to Lynn Morris, PhD, 1 Modderfontein Road, Sandringham 2131, Gauteng, South Africa and Jeffrey C.

Gildersleeve, 376 Boyles St, Building 376, Room 208, Frederick, MD 21702, USA.
}

E-mails: Iynnm@nicd.ac.za; gildersj@mail.nih.gov

Received: 26 June 2017; revised: 25 August 2017; accepted: 29 August 2017. 
neutralizing antibodies from 4 weeks postinfection, which typically target gp120 and persist throughout infection [2]. In a subset of HIV-infected individuals, broadly neutralizing antibodies (bNAbs), capable of neutralizing a large number of HIV strains, develop after 2-3 years of infection [2]. Understanding the factors that regulate $\mathrm{bNAb}$ development is a major research endeavour.

The trimeric HIV envelope glycoprotein is heavily glycosylated with between 25 and $30 \quad N$-linked glycosylation sites that account for half of its molecular mass, known as the glycan shield [3,4]. Although glycans are attached to the viral envelope through the host cell glycosylation pathways, they undergo limited processing, resulting in inefficiently trimmed glycans [5]. The glycan shield on trimeric gp120 is mostly comprised of densely packed high mannose, particularly Man $\alpha_{1-2}$ Man terminating glycans such as $\operatorname{Man}_{6-}$ ${ }_{9} \mathrm{GlcNAc}_{2}$, and complex N-linked glycans, although some $O$-linked glycans do occur [3,4,6-8]. In addition to protecting immunogenic sites on the virus, these glycans are also essential for glycoprotein folding and are thus often conserved [3-5].

A significant number of bNAbs target glycan-rich epitopes on the HIV envelope [9]. The N332 supersite on the V3 and V4 loops includes $\mathrm{Man}_{7-9}$ and are targeted by 2 G12 and some of the PGT antibodies (PGT125-131 and PGT135), whereas complex type glycans (A2, N2, and NA2) are targeted by PGT121-123 [10,11]. The N160, N156, and/or N173 sites of V2 region have high mannose $N$-linked glycans and sialylated $N$-linked glycans, which are bound by PG9/PG16 and the CAP256-VRC26 lineage [12-14]. High mannose Nlinked glycans have also been observed at the gp120-gp41 interface (targeted by 8ANC195 and 35O22) and CD4binding sites (targeted by HJ16 and PGV04) [3,9,15-17]. Despite the identification and characterization of a number of glycan-binding monoclonal bNAbs, the polyclonal serum antiglycan antibody responses to HIV infection in humans have not been well studied.

Glycan arrays have been developed to study the glycanbinding profiles of antibodies and have proven to be particularly useful in determining the types of glycan structures that are bound by HIV-1 bNAbs $[10,11,18-$ 25]. In addition, the antiglycan antibody responses in sera of nonhuman primates after Ad5hr-simian immunodeficiency virus (SIV) vaccination and SIV infection [26] and HIV vaccine responses in rabbits have been assayed on arrays $[20,27,28]$. Here, we studied serum antiglycan IgG antibody profiles of HIV-negative and HIV-positive individuals, including those who develop bNAbs, over 3 years of infection. Our aim was to determine whether elevated levels of serum antiglycan IgG antibodies are observed during HIV infection or unique to individuals who make bNAbs.

\section{Methods}

\section{Serum samples and ethics statement}

Sera from 47 South African Black women (27 HIVpositive and $20 \mathrm{HIV}$-negative) taken at four time-points (yearly for 3 years and, when available, prior to infection) were obtained from the Centre for the AIDS Programme of Research in South Africa (CAPRISA) 002 Acute Infection Study [29] and the 004 Tenofovir Gel Trial [30] cohorts. Among the 27 HIV-positive individuals, 12 developed bNAbs and 12 did not develop bNAbs, despite being infected for at least 2 years and having similar antigenic loads (Supplementary Table 1, http:// links.lww.com/QAD/B157) [31]. Sera were tested against a panel of 18 viruses comprising 6 subtype $A, 6$ subtype $B$, and 6 subtype $C$ viruses. Individuals with bNAbs were capable of neutralizing 33-94\% (median $53 \%$ ) of the panel, whereas those without bNAbs neutralized only $0-6 \%$. Three individuals whose sera neutralized $17-22 \%$ of the panel viruses were termed intermediate neutralizers. The HIV-positive samples were selected based on neutralization breadth and matched for viral load. Samples from $20 \mathrm{HIV}$-negative individuals were used as controls to assess normal fluctuations in glycan-binding over a 3-year period. Control reference serum, consisting of pooled human sera, used to assess reproducibility of the arrays, was purchased from Valley Biomedical Products and Services (Winchester, Virginia, USA). All human serum samples were heat-inactivated for $30 \mathrm{~min}$ in a $56^{\circ} \mathrm{C}$ water bath prior to binding on the glycan arrays. Similar experiments using samples from macaques showed no inhibitory effect on antibody function or antiglycan antibody profiles [26,32]. All timepoints from the same individual were run on the same day to minimize intraindividual variability, and samples from individuals with and without bNAbs were intermixed to minimize experimental biases. In addition, all samples were run in duplicate and averaged. This study received ethics clearance from the University of the Witwatersrand (M080470 and M111104). The CAPRISA Acute Infection study in adult women received ethical approval from the Universities of KwaZulu-Natal (E013/04), Cape Town (025/2004), and the Witwatersrand (MM040202), and informed consent was obtained from all study participants.

\section{Monoclonal antibodies}

Seven well characterized bNAbs were used to assess the ability of the glycan arrays to detect HIV-specific glycanbinding. PG16 and 2G12 were obtained from the NIH AIDS Reagent Program. PGT121, PGT125, PGT126, PGT128, and PGT130 were provided by IAVI's Neutralizing Antibody Center (Scripps Research Institute, La Jolla, California, USA).

\section{Glycan arrays}

Glycan arrays were composed of 337 components (of which 245 were unique structures, many of which were 
printed at multiple densities on the array surface), including $N$-linked carbohydrates, glycolipids, and glycopeptides (Supplementary Table 2, http://links.lww.com/QAD/ B157). Included in the array were ten controls (BSA, HSA, linkers, and fluorochromes) that were used to assess technical reproducibility and were excluded from downstream analysis. The arrays were generated as previously described [26], with the exception of the addition of a washable fluorescent dye, DyLight649 $(0.7 \mu \mathrm{g} / \mathrm{ml}$; ThermoScientific, Waltham, Massachusetts, USA) to the print buffer as an indicator of successful liquid deposition and spot morphology. Triton X-100 concentration was reduced to $0.0001 \%$ instead of $0.006 \%$ to produce smaller spots allowing additional glycans to be spotted onto the plate. The array format and binding assay were analyzed for reproducibility and validated with numerous antibodies and lectins as previously described [33-37]. All array experiments were done using sera diluted 1:50 in the absence of calcium. Other studies using these arrays have ruled out competition by lectins, such as mannose-binding lectin (MBL), under these conditions (unpublished data). Slides were scanned at $10 \mu \mathrm{m}$ resolution with a Genepix 4000A microarray scanner (Molecular Devices Corporation, Sunnyvale, California, USA) and analyzed with Genepix Pro 6.0 software as previously reported [33].

\section{gp120 competition assay}

To determine if glycan-binding profiles were HIVspecific, sera with high $\mathrm{Man}_{8}$ binding levels were incubated with purified monomeric ConC gp120 $(100 \mu \mathrm{g} / \mathrm{ml})$ or PBS alone at room temperature for $15 \mathrm{~min}$. Monomeric ConC gp120 was expressed as described in Gray et al. [38] and purified using a Galanthus Nivalis lectin (Stratagene, La Jolla, California, USA). Sera incubated with or without gp120 were run on the same glycan array slide to minimize variability. A total of three wells (six replicate spots) were analyzed.

\section{Statistical and data analysis}

All fold-change differences were calculated based on relative fluorescence unit (RFU) binding. Pearson correlations were used to calculate the coefficient of determination $\left(r^{2}\right)$ of glycan-binding between and within individuals. Two methods were used to assess levels of glycan-binding in HIV-positive samples relative to HIVnegative samples. The first method identified array components with binding levels at least two-fold higher than those observed in the HIV-negative samples and present in at least two HIV-infected individuals. In the second method, we identified components with at least two-fold increased binding over two consecutive time-points in postinfection samples in at least two individuals compared to matched preinfection samples. Two-sampled $t$ tests were used to compare the binding profiles of gp120 or PBS-treated sera in the gp120 competition assay and between the individuals who made bNAbs and those who did not. The resulting $P$ values were corrected for multiple testing using a Bonferroni correction and $P$ values 0.05 or less were considered significant.

\section{Results}

\section{Detection of monoclonal antibody binding on glycan arrays}

Seven well characterized monoclonal antibodies (mAbs) with broadly neutralizing activity were used to assess the array's ability to detect HIV-specific glycan-binding. These $\mathrm{mAbs}$ targeted high mannose $\mathrm{N}$-linked glycans and complex glycans on the V2 and V3 loops of gp120 $[10,11,24,39,40]$. A cut-off of at least $3000\left(\log _{2} 11\right)$ relative fluorescence values (RFUs) was used in order to compare our data to a previously published study [11].

Six of the seven mAbs bound to at least two glycans (Fig. 1) confirming previous reports $[10,11,24,39,40]$. The only $\mathrm{mAb}$ with no binding was PG16, which is known to target a trimer-specific epitope and has previously failed to bind on arrays [17]. The $\mathrm{mAb}$ 2G12 and the PGT antibodies, except PGT121, bound high mannose $N$-linked glycans $\mathrm{Man}_{8}$ and $\mathrm{Man}_{9}$ to varying levels. PGT121 bound NA2 (other glycans A2, A2F, and N2 previously associated with PGT121 $[10,11]$ were not part of this array). In addition, we found binding to thyroglobulin by PGT125, PGT128, and PGT130, whereas fatty acid-binding protein (FABP), ManT (branched $\mathrm{Man}_{3}$ glycan), and galactose- $\alpha$ (Gal- $\alpha$ ) were recognized by single mAbs. On the basis of these results, we concluded that the array used in this study was capable of capturing HIV-specific glycan-binding antibodies.

\section{Natural fluctuations in antiglycan IgG antibodies over 3 years}

To identify changes associated with HIV infection, it was necessary to first define natural fluctuations in serum antiglycan $\operatorname{IgG}$ antibodies in HIV-negative individuals. Previous longitudinal studies of human sera on glycan arrays have been limited to $1-3$ months [36], and because bNAbs take years to develop, we aimed to understand natural fluctuations in glycan-binding $\operatorname{IgG}$ antibodies over a longer timeframe. We therefore profiled 80 serum samples from $20 \mathrm{HIV}$-negative individuals (from the CAPRISA 002 and 004 cohorts) collected yearly for 3 years (time-points labeled as $0,1,2$, and 3 years).

As might be expected, we observed greater fluctuations over 3 years than seen in previous studies (data not shown) $[36,41]$. For all HIV-negative samples, $10 \%$ of the glycans varied by 2.6 -fold (typically used as a cut-off for healthy individuals [36]), 3\% by 4 -fold, and only $0.5 \%$ showed more than 10-fold changes. Fluctuations varied considerably between individuals with some (e.g. CAP11) showing fewer glycan changes between time-points, and 
(a)

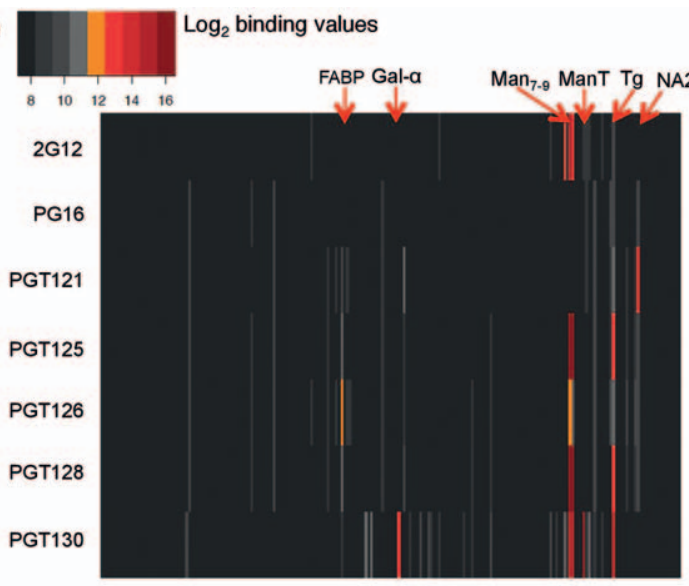

(b)

\begin{tabular}{|c|c|c|c|c|}
\hline bNAb & $\begin{array}{c}\begin{array}{c}\text { Array } \\
\text { Binding } \\
\text { (RFU }>3000)\end{array} \\
\end{array}$ & Type of Glycan & $\begin{array}{l}\text { Associated } \\
\text { Glycan(s) }\end{array}$ & Reference \\
\hline $2 \mathrm{G} 12$ & $\operatorname{Man}_{7-9}$ & $N$-linked high mannose & $\operatorname{Man}_{7-9}$ & $\begin{array}{l}\text { Scanlan et al., } \\
2002\end{array}$ \\
\hline PG16 & None & & \begin{tabular}{|c|}
$\mathrm{Man}_{5} \mathrm{GIcNA}_{2}$, \\
complex sialylated \\
$\mathrm{N}$-glycans \\
\end{tabular} & \begin{tabular}{|c|} 
Amin et al., 2013; \\
Shivatare et al., \\
2013 \\
\end{tabular} \\
\hline PGT121 & NA2 & $N$-linked glycan & $\mathrm{N} 2, \mathrm{NA} 2, \mathrm{~A} 2, \mathrm{~A} 2 \mathrm{~F}$ & $\begin{array}{l}\text { Mouquet et al., } \\
2012\end{array}$ \\
\hline PGT125 & $\operatorname{Man}_{8-9}, \mathrm{Tg}$ & $\begin{array}{c}N \text {-linked high mannose, } \\
\text { Thyroglobulin }\end{array}$ & $\operatorname{Man}_{8-9}$ & Walker et al., 2011 \\
\hline PGT126 & $\begin{array}{l}\text { Man }_{8} \\
\text { FABP }\end{array}$ & $\begin{array}{l}N \text {-linked high mannose, } \\
\text { Lipid binding protein }\end{array}$ & $\operatorname{Man}_{8-9}$ & Walker et al., 2011 \\
\hline PGT128 & $\operatorname{Man}_{8-9}, \mathrm{Tg}$ & $\begin{array}{c}N \text {-linked high mannose, } \\
\text { Thyroglobulin }\end{array}$ & $\operatorname{Man}_{8-9}$ & Walker et al., 2011 \\
\hline PGT130 & $\begin{array}{l}\text { Man }_{8-9}, \mathrm{Tg}, \\
\text { Gal-a, ManT }\end{array}$ & $\begin{array}{l}N \text {-linked high mannose, } \\
\text { Thyroglobulin, } \\
\text { galactose- } \alpha \text {, mannose. }\end{array}$ & $\operatorname{Man}_{8-9}$ & Walker et al., 2011 \\
\hline
\end{tabular}

(c)

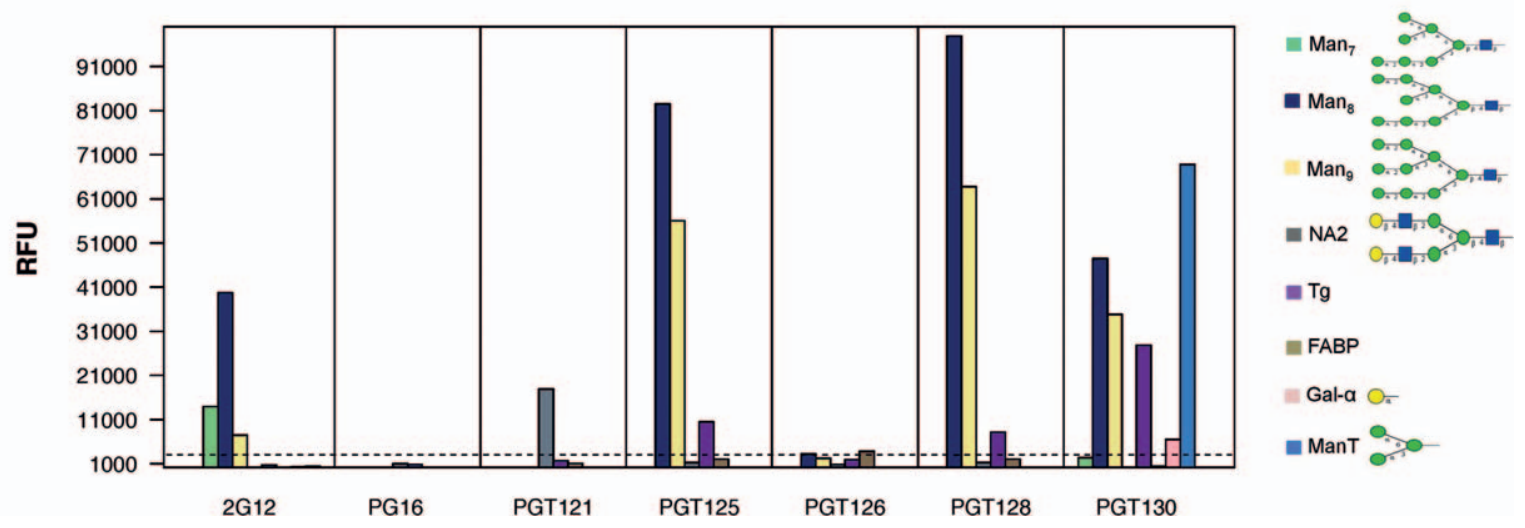

Fig. 1. Monoclonal antibody (mAb) glycan-binding profiles. (a) Heatmap of binding by each mAb on the glycan array. Shown are the $\log _{2}$-binding values of the seven mAbs for all glycans on the array. (b) Table comparing glycan-binding profiles from this array to previous studies. Listed are the glycans that had RFU-binding values at least 3000 ( $\log _{2} 11$, the cut-off used in previous studies). (c) Glycan-binding profiles of all seven mAbs for all glycans with RFU-binding at least 3000. Shown are the RFU-binding values for each of the mAbs tested for all eight glycans observed with binding at least 3000 on this array. RFU, relative fluorescence unit.

others (CAP39 and CAP54) with more drastic changes (Fig. 2a). By comparison, HIV-positive individuals showed similar fluctuations over time including some with more drastic changes (Fig. 2b). Despite these fluctuations, the overall IgG antibody glycan-binding profiles from the same individual at different time points were highly correlated based on Pearson correlations, with coefficient of determination $\left(r^{2}\right)$ values typically at least 0.9, irrespective of HIV infection. This is in contrast to correlations seen between different individuals, which showed more variation, where $r^{2}$ values were typically 0.8 or less (Fig. 2c).

Although substantial changes could be observed in some individuals at certain time-points irrespective of HIV infection, antiglycan antibody signals generally oscillated rather than continually increased or decreased throughout the 3 years of study. This result suggests a fluctuation about a steady-state level for essentially all the antibody populations measured in these individuals. Thus, we concluded that comparing a single time-point could result in a high proportion of false-positives, and that longitudinal sampling was necessary to accurately determine glycan-binding changes specifically related to HIV infection.

\section{Defining HIV-associated glycan-binding responses}

We devised two methods that used data from HIVnegative samples to identify responses associated with HIV-1 infection. In the first method, we compared 88 longitudinal samples from $27 \mathrm{HIV}$-positive individuals to 80 longitudinal samples from the 20 HIV-negative individuals. Binding needed to be at least two-fold higher than the highest level seen within the HIVnegative individuals and observed in at least two HIVpositive individuals to be considered elevated. In the second method, we focused on changes relative to preinfection, which were only available for 11 of the 27 HIV-infected individuals, selecting array components with at least two-fold increased binding in two consecutive time-points (to account for temporal oscillations) in postinfection samples. 
(a)

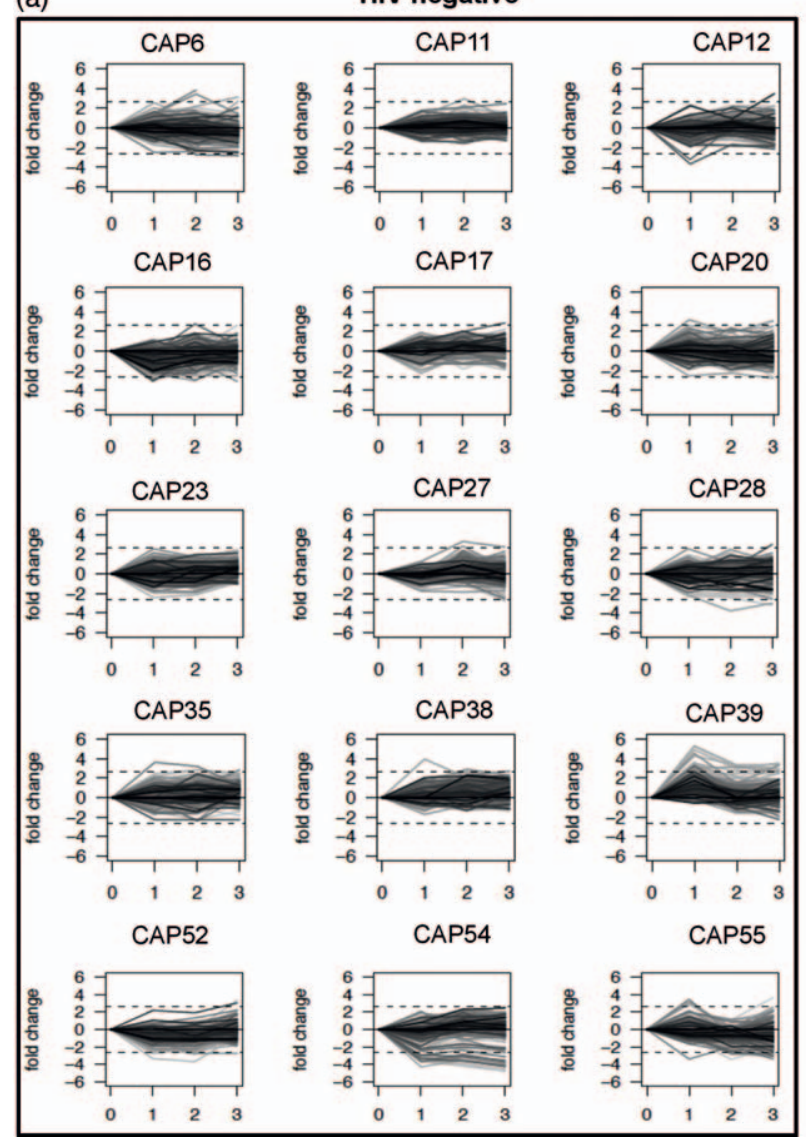

(b)

HIV positive
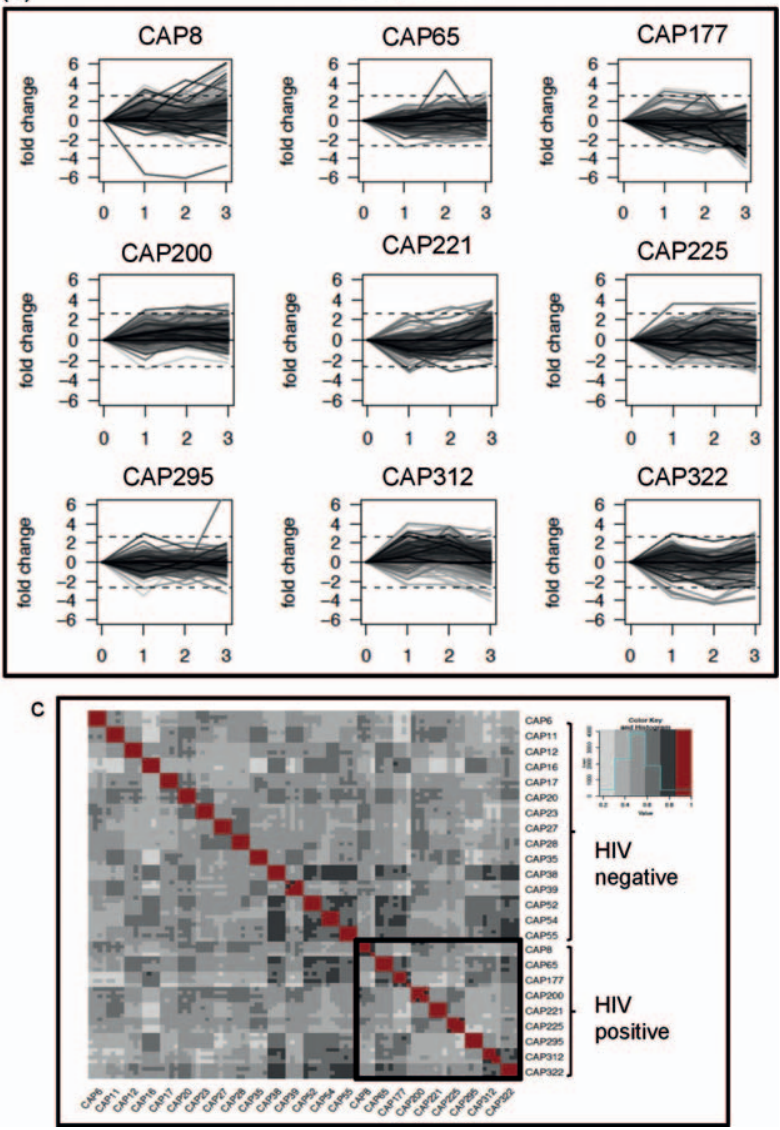

Fig. 2. Fluctuations in longitudinal antiglycan serum IgG. (a) Longitudinal fluctuations in HIV-negative individuals. Shown are fold-change differences in longitudinal serum IgG antibodies compared to year 0 for 15 of 20 HIV-negative individuals for whom all four time-points were available. Each line represents a different glycan spotted on the array. (b) Longitudinal fluctuations in HIVpositive individuals. Shown are the fold-change differences in longitudinal serum IgG antibodies compared to matched preinfection samples for nine of 27 HIV-infected individuals for which all four time-points were available, where each line represents a different glycan. (c) Correlation of longitudinal samples within and across individuals. Shown are the $r^{2}$ values of Pearson correlations comparing the RFU values of all glycans on the arrays for each of the four time-points for each of the participants shown in (a) and (b). The heat map is ordered so that all four time-points per individual are next to each other (timepoints not labeled), with the HIV-positive individuals in the bottom right corner. The correlations shown in the diagonal (mostly in red) represent each time-point within an individual, those outside the diagonal in gray represent the correlations compared across individuals.

A combination of these two methods identified 40 (out of 245) array components that were elevated in HIVpositive samples, including high mannose $N$-linked glycans, Tn-peptides, glycolipids, glycoproteins, Tfpeptides, and Lewis antigens (Supplementary Table 3, http://links.lww.com/QAD/B157). Most (36/40, 90\%) were elevated in postinfection samples compared to matched preinfection samples. Nine out of the 40 components were identified using both methods, and included $\mathrm{Man}_{8}, 4$ Tn-peptides [Ac-A-Tn(Thr)-S-G, AcS-Tn(Thr)-Tn(Thr)-G, Ac-S-Tn(Thr)-G-G, and Ac-PTn(Thr)-T-G], 2 glycolipids (GT2 and GT3), heat shock protein (HSP), and Fuc-b (Fig. 3). The highest levels of binding against $\mathrm{Man}_{8}$ were observed at 3 years postinfection, with two individuals having 15 -fold and 11.5-fold higher binding than the HIV-negative samples, respectively (Fig. 3a). In addition, these values were 6-8fold higher than the median of 220 previously studied healthy individuals from the United States [42]. Other Nlinked high mannose glycans $\left(\mathrm{Man}_{5}\right.$ and $\left.\mathrm{Man}_{9}\right)$, identified using only the first method, also showed very high levels of binding at 3 years postinfection, 53-fold and 7-fold, respectively. Increased binding to the Tn-peptides were observed throughout HIV infection, with the exception of Ac-P-Tn(Thr)-T-G, in which increased binding was mostly observed at 1 year postinfection (Fig. 3e). Likewise, binding against the two glycolipids and Fuc$\mathrm{b}$ were observed throughout infection, whereas elevated binding to HSP was mostly observed at 1 and 3 years postinfection (Fig. 3f-i). 
(a)

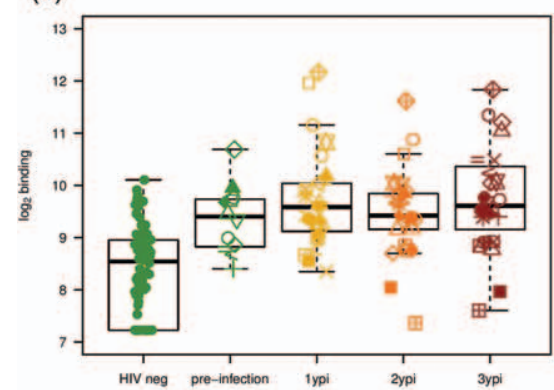

(d)

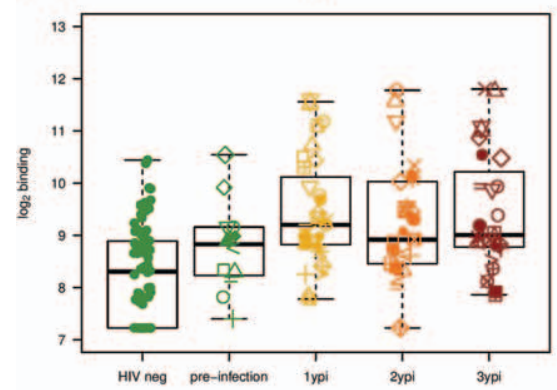

(g)

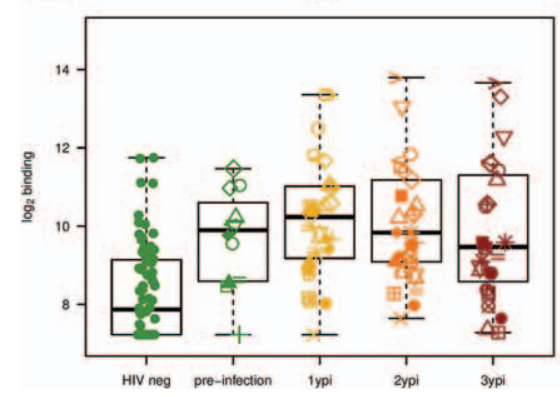

(b)

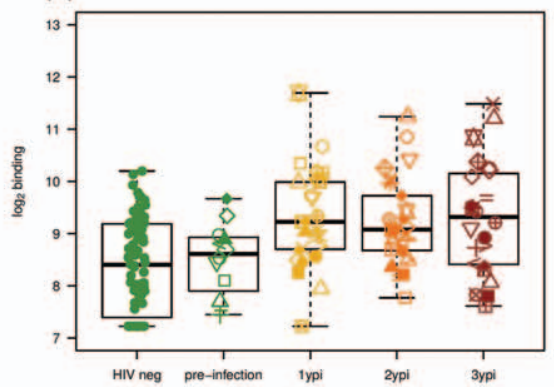

(e)

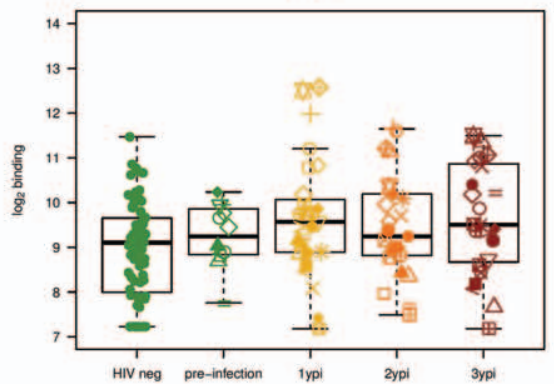

(h)

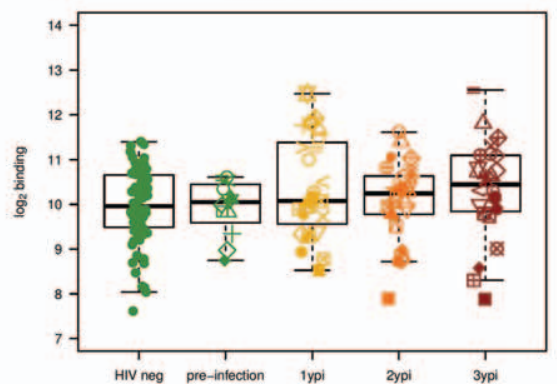

(c) Tn-2

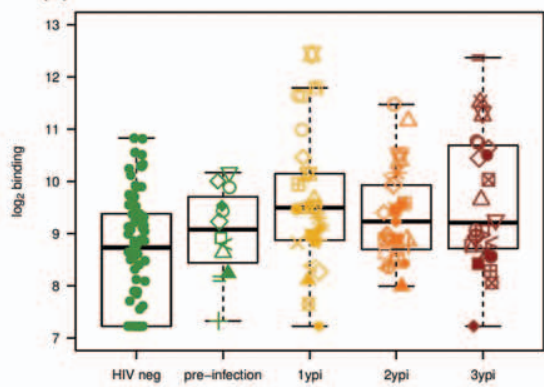

(f)

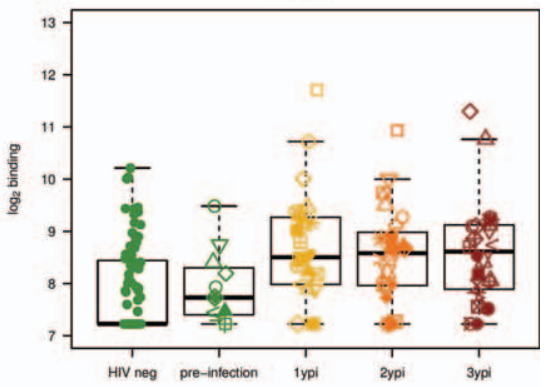

(i)

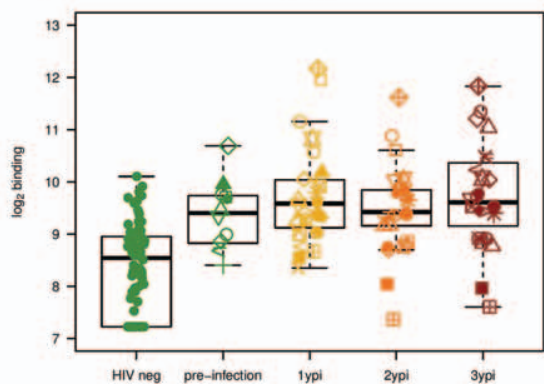

Fig. 3. Longitudinal glycan-binding profiles during HIV-1 infection. Shown are the $\log _{2}$-binding values for all serum samples. HIV-negative and preinfection (green), 1 year postinfection (ypi, in yellow), 2 years postinfection (orange), and 3 years postinfection (red). Each HIV-positive individual is shown using a different symbol. Tn-1 refers to Ac-A-Tn(Thr)-S-G, Tn-2 AcS-Tn(Thr)-Tn(Thr)-G, Tn-4 Ac-S-Tn(Thr)-G-G, and Tn-6 Ac-P-Tn(Thr)-T-G.

\section{Competition with gp120 suggests some} glycan-binding IgG antibodies to be HIV-specific Since increased glycan-binding may be due to hypergammaglobulinemia associated with HIV infection, we used a competition assay to determine what proportion of these antibodies was HIV-specific. Three-year postinfection sera from eight HIV-positive individuals (highlighted in Supplementary Table 1, http://links.lww.com/QAD/ B157), with high levels of binding to $\mathrm{Man}_{8}$, found on the HIV-1 trimer [3], were incubated with the HIV glycoprotein gp120 prior to glycan array binding (data from NA3, NA4, NGA2B, Sialyl LeA, or the Tf-peptides were not available in this experiment). As a control, gp120-incubated sera showed a 21.4-fold reduction in median binding to gp120 compared to the PBS-incubated sera (Fig. 4). We saw a 10.9-fold decrease in binding to $\mathrm{Man}_{8}$ following gp120 incubation,

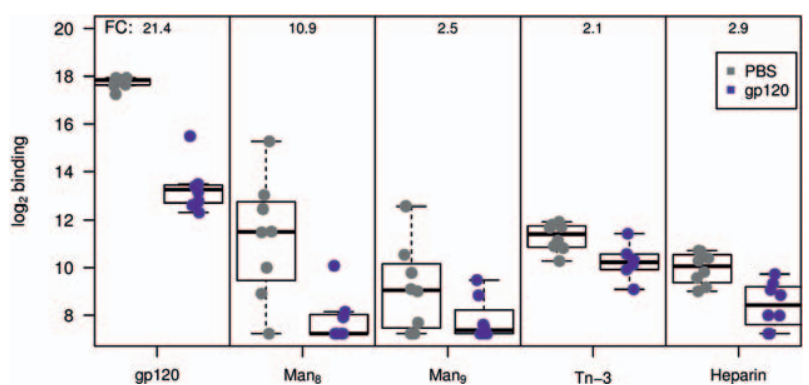

Fig. 4. Reduced glycan-binding following gp1 20 incubation. Shown are $\log _{2}$-binding values for 3 year postinfection sera from eight HIV-1-infected individuals incubated with PBS (gray) or gp120 (purple) prior to binding on the glycan array. The mean RFU fold-change differences (FCs) associated with each glycan are shown above the plot. Tn-3 refers to Ac-S$\mathrm{Tn}(\mathrm{Thr})-\mathrm{A}-\mathrm{G}$. RFU, relative fluorescence unit. 
and more than two-fold decreases in binding to $\mathrm{Man}_{9}$, Tn-3 [Ac-S-Tn(Thr)-A-G], and heparin. These data suggested that at least a proportion of these glycanbinding $\operatorname{IgG}$ antibodies are HIV-specific.

\section{Unique HIV-specific antiglycan IgG profiles in individuals who develop broadly neutralizing antibodies}

To determine if the elevated levels of binding observed during HIV infection were unique to individuals who developed bNAbs, the binding levels for the 40 array components that were elevated during infection were compared between the individuals that made bNAbs and individuals who did not develop bNAbs (Supplementary Table 1, http://links.lww.com/QAD/B157). For this analysis, we used samples from $10 \mathrm{bNAb}$ and 11 nonbNAb individuals at 3 years postinfection (Fig. 5). Although there were no statistically significant differences between the two groups, individuals who developed bNAbs tended to have higher levels of glycan-binding antibodies, particularly to some high mannose $\left(\mathrm{Man}_{3}\right.$ and NA4), Tn-peptides (Tn-1, Tn-2, Tn-3, and Tn-6), and HSP90. These data suggest that individuals who develop bNAbs may have a unique serological profile that could be informative for vaccine design.

\section{Discussion}

In this study, we used glycan microarray technology to profile $\operatorname{IgG}$ responses over 3 years of HIV-1 infection. We observed an increase in glycan-binding antibodies upon infection to 40 components on the array, including high mannose $N$-linked glycans, Tn-peptides, and glycolipids, some of which were confirmed to be HIV-specific following a reduction in binding after gp120 incubation. Furthermore, individuals who made bNAbs tended to have elevated levels of glycan-binding compared to those who did not, despite chronic HIV infection. This study is the most comprehensive analysis of antiglycan $\operatorname{IgG}$ antibody responses induced by HIV infection and highlights a potentially unique glycan-binding profile in individuals who develop bNAbs.

Since glycans are targeted by the human immune system, we first profiled serum IgG antibodies in HIV-negative individuals with similar demographics over a 3-year time frame to determine baseline antiglycan IgG antibody levels. These profiles were highly correlated within an individual at different time-points, with antibody subpopulations fluctuating about a steady state, suggesting a highly co-ordinated and controlled response to antigenic stimuli. As expected, these fluctuations varied considerably from one individual to another and were greater than those observed in earlier studies over a short time period [36,41]. This analysis highlights the importance of having matched controls when studying antiglycan responses to infection.
Two different approaches were devised to account for natural glycan-binding variation, which identified a number of $\mathrm{IgG}$ responses that were the result of HIV infection. Antibodies to high mannose glycans, such as $\mathrm{Man}_{8}$, were one of the most noteworthy responses, with certain individuals producing exceptionally high signals compared to HIV-negative control individuals. In addition, these antibodies were partially depleted by preincubation with gp120, providing support that they are HIV-specific. Responses to high mannose $N$-linked glycans tended to occur during chronic infection, with the highest levels of binding seen at 3 years postinfection. This time frame is in line with the development of bNAbs, although responses to $\mathrm{Man}_{8}$ and $\mathrm{Man}_{9}$ did not show a significant association with breadth possibly because these are also targeted by strain-specific antibodies.

In addition to high mannose antibodies, we observed HIVassociated responses to Tn-peptides, glycolipids, glycoproteins, Lewis antigens, Tf-peptides, and other array components, some of which were also higher among individuals with bNAbs. Increased binding to Tn-peptides has also been observed following SIV vaccination and SIV infection using this same array [26]. Tn-peptides are precursors of O-linked glycans, and in normal mammalian cells the Tn-portion of the O-linked glycans are masked during the glycosylation pathway. However, in HIV infection, the normal glycosylation pathways are altered revealing the Tn-portion of these $O$-linked glycans on the glycan shield potentially rendering them more immunogenic [26]. Interestingly, anti-Tn-peptide antibodies have been associated with the neutralization of HIV-1 by preventing fusion of the virus into infected cells $[43,44]$. Furthermore, a recent study has revealed how O-linked glycans on viral surfaces are used to initiate immune responses at mucosal surfaces [45].

Similarly, other glycans that we identified have previously been associated with HIV. Ganglioside glycosphingolipids are found on the HIV-1 envelope and have been associated with the uptake of HIV-1 into mature dendritic cells [46-49]. These glycolipids attach to the cellular receptor Siglec-1 enabling the incorporation of HIV-1 into the dendritic cell and the subsequent transfer to $\mathrm{CD}^{+} \mathrm{T}$ cells [49]. Thyroglobulin (which was also bound by three of the PGT mAbs) is a glycoprotein produced by the thyroid gland that is dysregulated in HIV-infected individuals [50-54]. Thyroglobulin is highly glycosylated and binds very strongly to ConA, suggesting that the binding noted in this array may be through high mannose. Finally, heparin has previously been observed to inhibit viral infectivity including HIV1 , and thus its elevation among those with bNAbs is of interest [55-58].

HIV-1 infection has been associated with a wide range of B-cell dysfunctions, including hypergammaglobulinemia (increased levels of circulating $\mathrm{IgG}$ ), malignancies, 


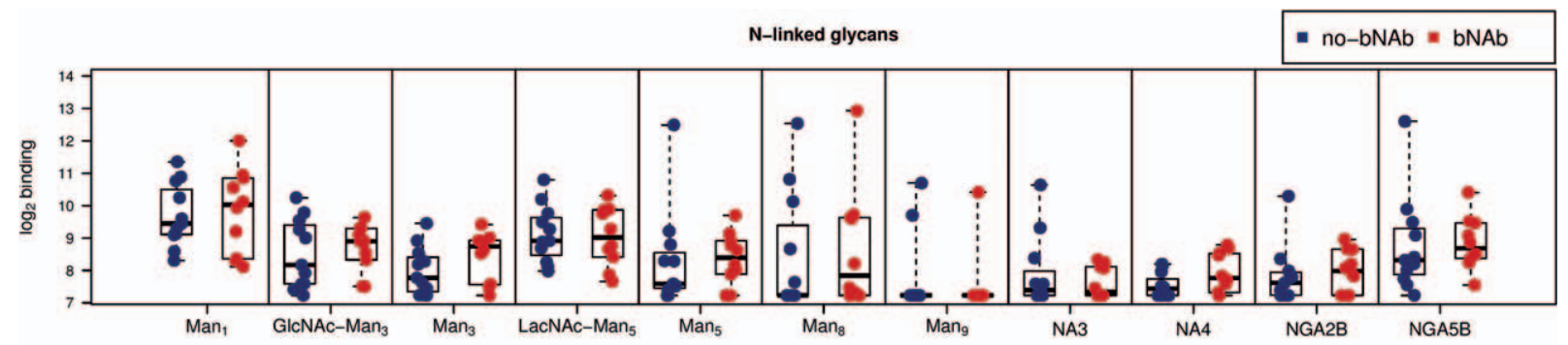

Tn-peptides

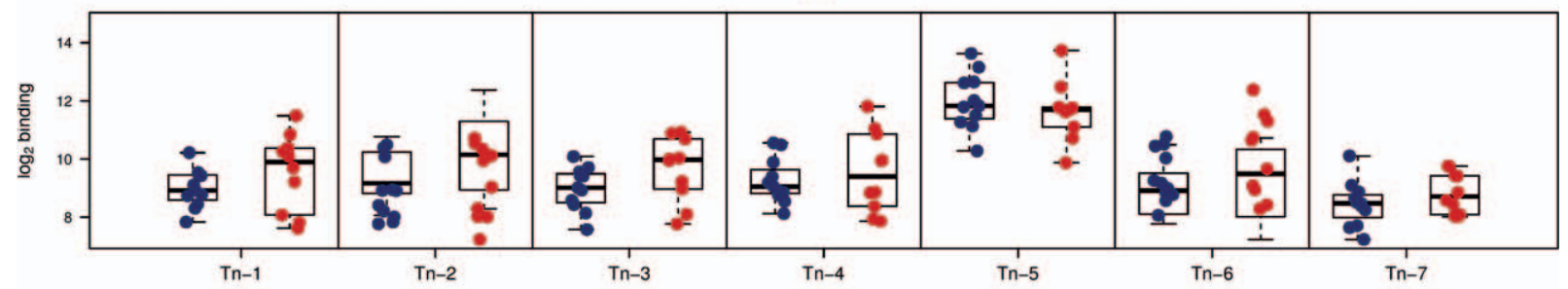

Glycolipids
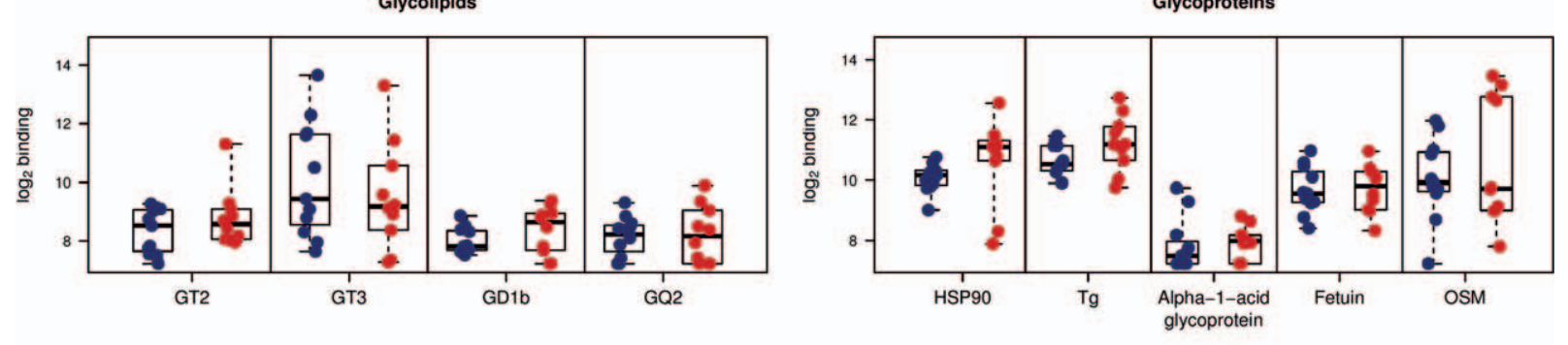

Lewis
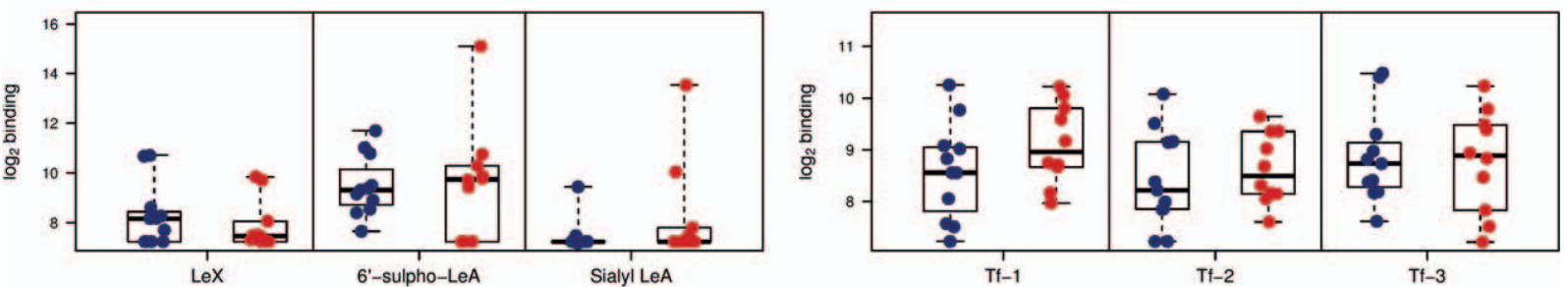

Other Glycans

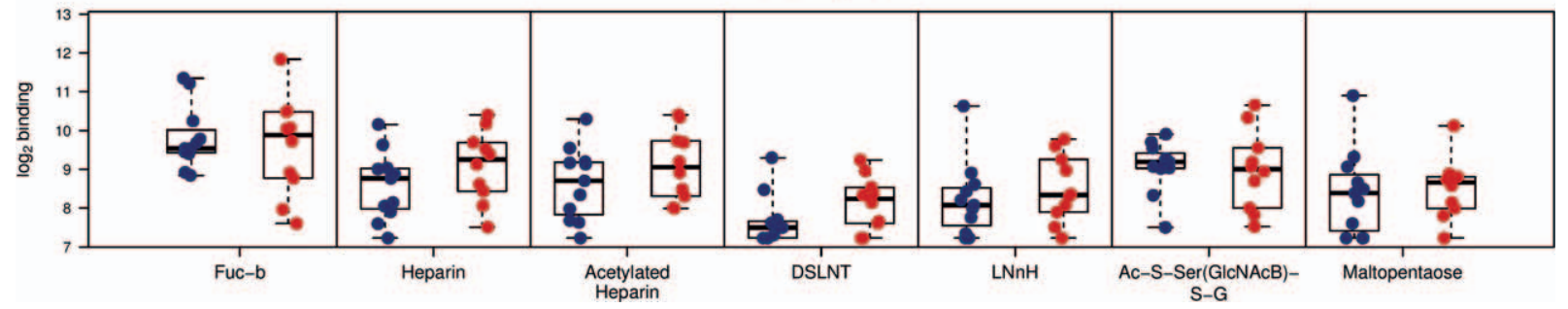

Fig. 5. Differences in glycan-binding between individuals with and without bNAbs. Shown are the log $\log _{2}$-binding values at 3 years postinfection for the individuals who developed bNAbs $(n=10)$ compared to those who did not develop bNAbs $(n=11)$ despite chronic HIV infection, for each of the 40 array components that were elevated during HIV infection. Tn- 1 refers to Ac-A-Tn(Thr)-SG, Tn-2 Ac-S-Tn(Thr)-Tn(Thr)-G, Tn-3 Ac-S-Tn(Thr)-A-G, Tn-4 Ac-S-Tn(Thr)-G-G, Tn-5 Ac-S-Tn(Thr)-S-G, Tn-6 Ac-P-Tn(Thr)-T-G, Tn-7 Ac-Tn(Ser)-Tn(Ser)-Tn(Ser)-G, Tf-1 DTVPLPTAHGTSASSTG, Tf-2 DTVPLP-TF(Thr)-AHGTSASSTG, and Tf-3 DTVPLPTAHGTTF(Ser)-ASSTG. bNAbs, broadly neutralizing antibodies.

exhaustion, an increase in subsets of B cells not found in healthy individuals, and polyclonal activation $[1,59,60]$. Although we observed a number of changes in HIVinfected individuals, the overall IgG antibody profiles and the average signals on the array were largely unchanged within a given individual before and after acquiring HIV infection. Therefore, the changes we identified using our two strategies are not simply a result of global changes in 
antibody levels or general dysregulation of antibody production, but rather a specific response to HIV infection. It is possible that greater changes might be observed if all antibodies were assessed and not just those that bind glycans.

The study had some limitations. First, we were only able to assess the HIV specificity of antibodies using gp120 and thus would not have detected glycan-binding antibodies to epitopes in gp41 or those present only on the trimeric envelope structure. In addition, only samples with high levels to $\mathrm{Man}_{8}$ were used in the gp120 competition assay and not those with high levels to other array components. It is likely therefore that we have underestimated the proportion of glycan-binding $\operatorname{IgG}$ antibodies that are HIV-specific. Second, we used stringent criteria to identify HIV-associated IgG responses. Although our goal was to minimize false-positives, this approach could have missed HIV-associated responses that occurred infrequently or were below our cut-off. Third, the array contained only a small fraction of the glycans found in the human glycome and thus some important responses may not have been detected. Lastly, the comparison of individuals who develop bNAbs to those who do not may be limited by our sample size; increased numbers may show more statistically significant results.

Nonetheless, this study is the first to highlight natural fluctuations in a diverse spectrum of glycan-binding IgG antibodies over a 3-year time frame in healthy and HIVinfected individuals. Through this, we have shown that HIV induced glycan-binding antibodies against $N$-linked glycans, which are known to be targets of bNAbs, but also against O-linked glycans and glycolipids, whose role in the HIV envelope trimer is less clear. Since the responses to $N$-linked high mannose glycans were seen later in infection, whereas responses to Tn-peptides and glycolipids were seen constantly throughout infection, further investigation into these glycans may be warranted.

\section{Acknowledgements}

We would like to thank the participants of the CAPRISA 002 and 004 studies from whom these samples were obtained, and also Natasha Samsunder and the CAPRISA laboratory and clinical staff involved in sample collection and processing. We also thank Dr Mashudu Madzivhandila and Tandile Hermanus for generating the neutralization data and Nancy Tumba for producing the gp120 used in the competition studies. We thank the Consortium for Functional Glycomics (GM62116; The Scripps Research Institute), Professor Tom Tolbert (University of Kansas), Professor Lai-Xi Wang (University of Maryland), Professor Xuefei Huang (Michigan State University), and Dr Joseph Barchi (National Cancer Institute) for contributing glycans for the array.
Funding: This project was supported by the Poliomyelitis Research Foundation (PRF), University of the Witwatersrand Health Sciences Faculty Research Council, the South African National Research Foundation Centre of Excellence in HIV Prevention, the South African Department of Science and Technology, and the National Institutes of Health/National Institute of Allergy and Infectious Diseases R01 grant number: R01AI104387. In addition, this project was supported in part by the intramural research program of the NIH, NCI.

Author contributions: C.S. designed and conducted experiments, analyzed the data, and wrote the manuscript; S.C. and S.W. conducted additional glycan-array experiments; C.T.C. provided guidance on glycan-array experiments and data analysis; N.G., Q.A.K., and S.S.A.K. provided clinical samples; P.L.M. provided guidance on the manuscript; J.C.G. supervised the project and provided guidance on data analysis; and L.M. designed experiments, provided guidance on data analysis, and supervised the project. All authors commented on the manuscript.

\section{Conflicts of interest}

C.S. was supported by the Columbia UniversitySouthern African Fogarty AIDS International Training and Research Program (AITRP) through the Fogarty International Center, National Institutes of Health (grant \# 5 D43 TW000231). P.L.M. is supported by the South African Research Chairs Initiative of the Department of Science and Technology and the NRF (Grant No 98341). C.T.C. was supported by a Pharmacology Research Associated Training Fellowship, NIGMS. CAPRISA is funded by the National Institute of Allergy and Infectious Diseases (NIAID), National Institutes for Health (NIH), and US Department of Health and Human Services (Grant: AI51794).

\section{References}

1. Tomaras GD, Yates NL, Liu P, Qin L, Fouda GG, Chavez LL, et al. Initial B-cell responses to transmitted human immunodeficiency virus type 1: virion-binding immunoglobulin $M$ (IgM) and IgG antibodies followed by plasma antigp41 antibodies with ineffective control of initial viremia. / Virol 2008; 82:12449-12463.

2. Burton DR, Mascola JR. Antibody responses to envelope glycoproteins in HIV-1 infection. Nature Immunol 2015; 16:571-576.

3. Behrens AJ, Vasiljevic S, Pritchard LK, Harvey DJ, Andev RS, Krumm SA, et al. Composition and antigenic effects of individual glycan sites of a trimeric HIV-1 envelope glycoprotein. Cell Rep 2016; 14:1-12.

4. Pancera M, Zhou T, Druz A, Georgiev IS, Soto C, Gorman J, et al. Structure and immune recognition of trimeric prefusion HIV-1 Env. Nature 2014; 514:455-461.

5. Bonomelli C, Doores K, Dunlop C, Thaney V, Dwek R, Burton $D$, et al. The glycan shield of HIV is predominantly oligomannose independently of production system or viral clade. PLOS One 2011; 6:e23521.

6. Doores KJ, Bonomelli C, Harvey DJ, Snezana V, Dwek RA, Burton DR, et al. Envelope glycans of immunodeficiency virions are almost entirely oligomannose antigens. Proc Natl Acad Sci 2010; 107:13800-13805. 
7. Go EP, Liao HX, Alam SM, Hua D, Haynes BF, Desaire H. Characterization of host-cell line specific glycosylation profiles of early transmitted/founder HIV-1 gp120 envelope proteins. J Proteome Res 2013; 12:1223-1234.

8. Zhu X, Borchers C, Bienstock RJ, Tomer KB. Mass spectrometric characterization of the glycosylation pattern of HIV-gp120 expressed in CHO cells. Biochemistry 2000; 39:11194-11204.

9. Wibmer CK, Moore PL, Morris L. HIV broadly neutralizing antibody targets. Curr Opin HIV AIDS 2015; 10:1-8.

10. Mouquet H, Scharf L, Euler Z, Liu Y, Eden C, Scheid I, et al. Complex-type $\mathrm{N}$-glycan recognition by potent broadly neutralizing HIV antibodies. Proc Natl Acad Sci 2012; 109:E3268-E3277.

11. Walker LM, Huber M, Doores KJ, Falkowska E, Pejchal R, Julien $J-P$, et al. Broad neutralization coverage of HIV by multiple highly potent antibodies. Nature $2011 ; \mathbf{4 7 7}$ :466-470.

12. Doria-Rose NA, Bhiman JN, Roark RS, Schramm CA, Gorman J, Pancera $M$, et al. A new member of the V1V2-directed CAP256VRC26 lineage that shows increased breadth and exceptional potency. I Virol 2015; 90:76-91.

13. Doria-Rose NA, Schramm CA, Gorman J, Moore PL, Bhiman JN, DeKosky BJ, et al. Developmental pathway for potent V1V2directed HIV-neutralizing antibodies. Nature 2014; 509:5562.

14. Pancera M, Shahzad-UI-Hussan S, Doria-Rose NA, McLellan JS, Bailer RT, Dai K, et al. Structural basis for diverse N-glycan recognition by HIV-1-neutralizing V1-V2-directed antibody PG16. Nature Struct Mol Biol 2013; 20:804-813.

15. Balla-Jhagjhoorsingh SS, Corti D, Heyndrickx L, Willems E, Vereecken K, Davis D, et al. The $\mathbf{N 2 7 6}$ glycosylation site is required for HIV-1 neutralization by the CD4 binding site specific HJ16 monoclonal antibody. PLOS One 2013; 8:e68863.

16. Scharf L, Scheid J, Lee J, West A, Chen C, Gao H, et al. Antibody 8ANC195 reveals a site of broad vulnerability on the HIV-1 envelope spike. Cell Rep 2014; 7:785-795.

17. Huang J, Kang BH, Pancera M, LeeJH, Tong T, Feng Y, et al. Broad and potent HIV-1 neutralization by a human antibody that binds the gp41-gp1 20 interface. Nature 2014; 515:138-142.

18. Adams E, Ratner D, Bokesch H, McMahon J, O'Keefe B, Seeberger $\mathrm{P}$. Oligosaccharide and glycoprotein microarrays as tools in HIV glycobiology glycan-dependent gp120/protein interactions. Chem Biol 2004; 11:875-881.

19. Calarese D, Lee H-K, Huang C-Y, Best M, Astronomo R, Stanfield $R$, et al. Dissection of the carbohydrate specificity of the broadly neutralizing anti-HIV-1 antibody 2G12. Proc Natl Acad Sci USA 2005; 102:13372-13377.

20. Dunlop DC, Bonomelli C, Mansab F, Vasiljevic S, Doores KJ Wormald MR, et al. Polysaccharide mimicry of the epitope of the broadly neutralizing anti-HIV antibody, 2G12, induces enhanced antibody responses to self oligomannose glycans. Glycobiology 2010; 20:812-823.

21. Falkowska E, Le KM, Ramos A, Doores KJ, Lee JH, Blattner $\mathrm{C}$, et al. Broadly neutralizing HIV antibodies define a glycandependent epitope on the prefusion conformation of gp41 on cleaved envelope trimers. Immunity 2014; 40:657-668.

22. Julien JP, Sok D, Khayat R, Lee JH, Doores KJ, Walker LM, et al. Broadly neutralizing antibody PGT121 allosterically modulates CD4 binding via recognition of the HIV-1 gp120 V3 base and multiple surrounding glycans. PLoS Pathogens 2013; 9:e1003342.

23. Pejchal R, Doores K, Walker L, Khayat R, Huang P-S, Wang S-K, et al. A potent and broad neutralizing antibody recognizes and penetrates the HIV glycan shield. Science 2011; 334:10971103.

24. Shivatare SS, Chang SH, Tsai TI, Ren CT, Chuang HY, Hsu L, et al. Efficient convergent synthesis of bi-, tri-, and tetraantennary complex type N-glycans and their HIV-1 antigenicity. I Am Chem Soc 2013; 135:15382-15391.

25. Wibmer CK, Gorman J, Ozorowski G, Bhiman JN, Sheward DJ, Elliott DH, et al. Structure and recognition of a novel HIV-1 gp120-gp41 interface antibody that caused MPER exposure through viral escape. PLoS Pathog 2017; 13:e1006074.

26. Campbell CT, Llewellyn SR, Demberg T, Morgan IL, RobertGuroff M, Gildersleeve JC. High-throughput profiling of antiglycan humoral responses to SIV vaccination and challenge. PLoS One 2013; 8:e75302.

27. Astronomo R, Kaltgrad E, Udit A, Wang S-K, Doores K, Huang $C-Y$, et al. Defining criteria for oligomannose immunogens for HIV using icosahedral virus capsid scaffolds. Chem Biol 2010; 17:357-370.
28. Luallen R, Lin J, Fu H, Cai K, Agrawal C, Mboudjeka I, et al. An engineered Saccharomyces cerevisiae strain binds the broadly neutralizing human immunodeficiency virus type 1 antibody 2G12 and elicits mannose-specific gp120-binding antibodies. I Virol 2008; 82:6447-6457.

29. Van Loggerenberg F, Mlisana K, Williamson C, Auld S, Morris L, Gray C, et al. Establishing a cohort at high risk of HIV infection in South Africa: challenges and experiences of the CAPRISA 002 acute infection study. PLOS One 2008; 3:e1954.

30. Abdool Karim Q, Abdool Karim SS, Frohlich JA, Grobler AC, Baxter C, Mansoor LE, et al. Effectiveness and safety of Tenofovir gel, an antiretroviral microbicide, for the prevention of HIV infection in women. Science 2010; 329:1168-1174.

31. Gray ES, Madiga M, Hermanus T, Moore P, Wibmer C, Tumba $\mathrm{N}$, et al. The neutralization breadth of HIV-1 develops incrementally over four years and is associated with CD4+ T cell decline and high viral load during acute infection. / Virol 2011; 85:4828-4840.

32. Montefiori DC. Measuring HIV neutralization in a luciferase reporter gene assay. Methods Mol Biol 2009; 485:395-405.

33. Campbell C, Zhang Y, Gildersleeve J. Construction and use of glycan microarrays. Curr Protocols Chem Biol 2010; 2:37-53.

34. Manimala J, Li Z, Jain A, VedBrat S, Gildersleeve JC. Carbohydrate array analysis of anti-Tn antibodies and lectins reveals unexpected specificities: implications for diagnostic and vaccine development. ChemBioChem 2005; 6:2229-2241.

35. Manimala J, Roach T, Li Z, Gildersleeve J. High-throughput carbohydrate microarray profiling of 27 antibodies demonstrates widespread specificity problems. Glycobiology 2007; 17:17C-23C

36. Oyelaran O, MCShane LM, Dodd L, Gildersleeve JC. Profiling human serum antibodies with a carbohydrate antigen microarray. I Proteome Res 2009; 8:4301-4310.

37. Wang L, Cummings RD, Smith DF, Huflejt M, Campbell CT, Gildersleeve JC, et al. Cross-platform comparison of glycan microarray formats. Glycobiology 2014; 24:507-517.

38. Gray ES, Moody A, Wibmer CK, Chen X, Marshall D, Amos J, et al. Isolation of a monoclonal antibody that targets the alpha2 helix of gp120 and represents the initial autologous neutralizing-antibody response in an HIV-1 subtype C-infected individual. J Virol 2011; 85:7719-7729.

39. Amin MN, McLellan JS, Huang W, Orwenyo I, Burton DR, Koff WC, et al. Synthetic glycopeptides reveal the glycan specificity of HIV-neutralizing antibodies. Nature Chem Biol 2013; 9:521526.

40. Scanlan C, Pantophlet R, Wormald M, Saphire E, Stanfield R, Wilson $\mathrm{I}$, et al. The broadly neutralizing antihuman immunodeficiency virus type 1 antibody 2G12 recognizes a cluster of $(\mathbf{1} \rightarrow \mathbf{2}$ mannose residues on the outer face of gp120. / Virol 2002; 76:7306-7321

41. Zhang Y, Campbell C, Li Q, Gildersleeve J. Multidimensional glycan arrays for enhanced antibody profiling. Mol BioSyst 2010; 6:1583-1591.

42. Muthana SM, Gildersleeve JC. Factors affecting antiglycan IgG and IgM repertoires in human serum. Scientific Rep 2016; 6:19509.

43. Hansen JES, Nielsen C, Arendrup M, Olofsson S, Mathiesen L, Nielsen JO, et al. Broadly neutralizing antibodies targeted to mucin-type carbohydrate epitopes of human immunodeficiency virus. / Virol 1991; 65:6461-6467.

44. Hansen JES, Clausen H, Hu SL, Nielsen JO, Olofsson S. An Olinked carbohydrate neutralization epitope of HIV-1 gp120 is expressed by HIV-1 env gene recombinant vaccinia virus. Arch Virol 1992; 126 (1-4):11-20.

45. Iversen MB, Reinert LS, Thomsen MK, Bagdonaite I, Nandakumar R, Cheshenko N, et al. An innate antiviral pathway acting before interferons at epithelial surfaces. Nature Immunol 2016; 17:150-158.

46. Hatch SC, Archer J, Gummuluru S. Glycosphingolipid composition of human immunodeficiency virus type 1 (HIV-1) particles is a crucial determinant for dendritic cell-mediated HIV1 trans-infection. J Virol 2009; 83:3496-3506.

47. Izquierdo-Useros N, Lorizate M, Contreras FX, Rodriguez-Plata MT, Glass B, Erkizia I, et al. Sialyllactose in viral membrane gangliosides is a novel molecular recognition pattern for mature dendritic cell capture of HIV-1. PLOS Biol 2012; 10:e1001315. 
48. Izquierdo-Useros N, Lorizate M, McLaren P, Telenti A, Krausslich H-G, Martinez-Picado J. HIV-1 capture and transmission by dendritic cells: the role of viral glycolipids and cellular receptor siglec-1. PLOS Pathog 2014; 10:e1004146.

49. Puryear WB, Yu X, Ramirez A, Reinhard BM, Gummuluru S. HIV-1 incorporation of host-cell-derived glycosphingolipid GM3 allows for capture by mature dendritic cells. Proc Nat/ Acad Sci 2012; 109:7475-7480.

50. De Carvalho LG, Teixeira PdFdS, Panico ALBG, Cohen MV, Fernanda M, Pinheiro MC, et al. Evaluation of thyroid function and autoimmunity in HIV infected women. Arch Endocrinol Metab 2013; 57:450-456.

51. Fundarò C, Olivieri A, Rendeli $C$, Genovese $O$, Martino AM, D'Archivio $M$, et al. Occurrence of antithyroid autoantibodies in children vertically infected with HIV-1. J Pediatr Endocrinol Metab 1998; 11:745-750.

52. Hoffmann CJ, Brown TT. Thyroid function abnormalities in HIV infected patients. Clin Infect Dis 2007; 45:488-494.

53. Noureldeen A, Qusti SY, Khoja GM. Thyroid function in newly diagnosed HIV infected patients. Toxicol Indust Health 2012; 30:919-925.
54. Ownby RL. Thyroid function and depression in HIV-1 infection. World J AIDS 2012; 02:279-285.

55. Baba M, Pauwels R, Balzarini J, Arnout J, Desmyter J, De Clercq E. Mechanism of inhibitory effect of dextran sulfate and heparin on replication of human immunodeficiency virus in vitro. Proc Natl Acad Sci 1988; 85:6132-6136.

56. Harrop HA, Rider CC. Heparin and its derivatives bind to HIV-1 recombinant envelope glycoproteins, rather than to recombinant HIV-1 receptor, CD4. Glycobiology 1998; 8:131-137.

57. Howell AL, Taylor TH, Miller JD, Groveman DS, Eccles EH, Zacharski LR. Inhibition of HIV-1 infectivity by low molecular weight heparin. Int J Clin Lab Res 1996; 26:124-131.

58. Nagumo $T$, Hoshino $H$. Heparin inhibits infectivity of human immunodeficiency virus in vitro. Japanese J Cancer Res 1988; 79:9-11.

59. Moir S, Fauci AS. B-cell exhaustion in HIV infection: the role of immune activation. Curr Opin HIV AIDS 2014; 9:472-477.

60. Morris L, Binley JM, Clas BA, Bonhoeffer S, Astill TP, Kost R, et al. HIV-1 antigen-specific and -nonspecific B cell responses are sensitive to combination antiretroviral therapy. J Exp Med 1998; 188:233-245. 